\title{
Sobre a Afetividade na Odontologia para Bebês
}

Resumo: Este artigo é uma síntese da dissertação de mestrado "A afetividade na Odontologia para bebês: lugares e nuances", defendida na Universidade de São Paulo. A partir da perspectiva teórica de Guirado (1986 e 1987), com a colaboração de três odontopediatras, investigou-se a afetividade na Odontologia para bebês por meio de análise de representações de verbalizações das dentistas em vinte sessões clínicas e entrevistas individualizadas. Depreenderam-se, deste estudo, temáticas específicas, como a indiferenciação profissional-paciente e as possibilidades de transformação nas relações na área pesquisada.

Palavras-Chave: Afetividade, relação, Odontologia, bebês.

Abstract: This paper is a synthesis of the master's degree dissertation "The Affectivity in the Dentistry for Babies: Places and Nuances" held in the University of São Paulo. From Guirado's theorectical perspective (1986 e 1987), with the collaboration of three child dentists, there was an investigation of the affectivity in the Dentistry for babies through the representation analysis of professionals' speeches in twenty clinical sessions and personal interviews. Specific themes as the indiscrimination between dentist and patient as well as the possibility of transformation of the relationships of the researched area were concluded from this study. Key Words: Affectivity, relationship, Dentistry, babies.

\section{Ricardo Azevedo Barreto}

\section{Bacharel em Psicologia} e psicólogo - USP Mestre em Psicologia USP. Professor dos cursos de Psicologia e Odontologia da UNIT-SE

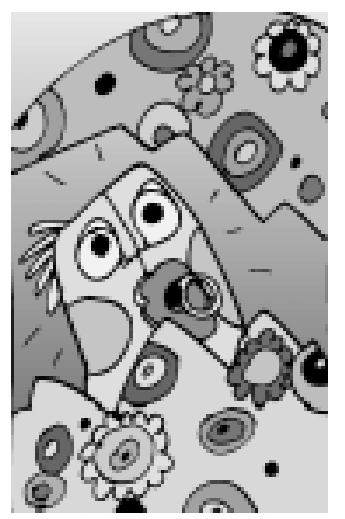

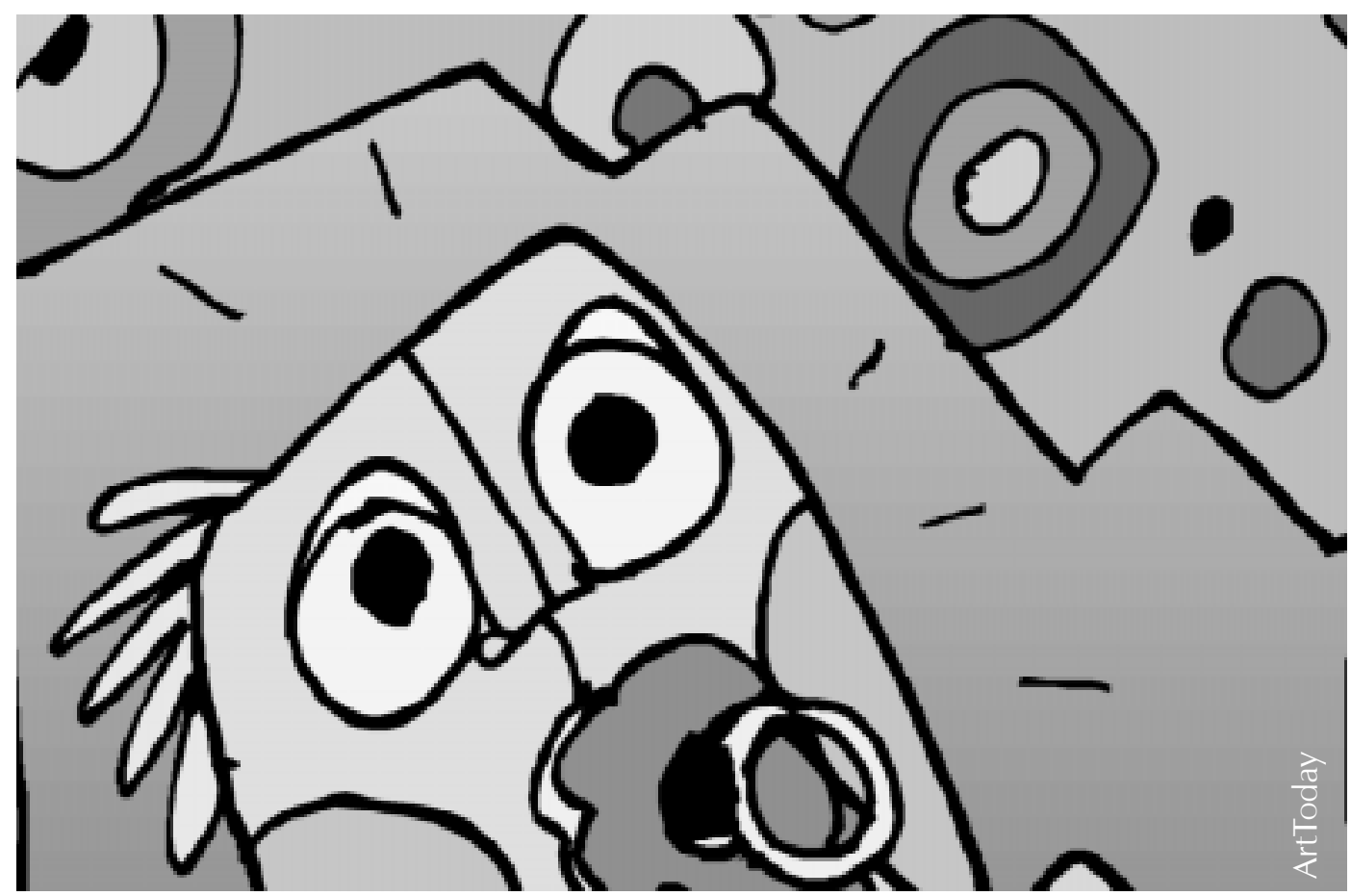

O campo de contribuição psicológica à Odontologia é amplo e fértil, porém pouco explorado.

Dentre os autores sobre o assunto, encontram-se Moraes e Pessoti (1993), que ressaltaram o equilibrismo exigido dos dentistas em suas práticas, sinalizando que as mesmas não são fáceis.

Mais especificamente sobre a Odontopediatria, inconscientes; Klatchoian (1992) delineou a perspectiva da relação, inclusive a possibilidade de identificação profissional-paciente.

A Odontologia para bebês é uma ramificação odontopediátrica bastante nova e transformadora, que se dedica à clientela de até três anos de idade, como enfatizaram Walter, Ferelle e Issao (1996), bem como Corrêa e Maia (1998). Tal área carece, sobretudo, de investigação psicológica. 
Diante do quadro apresentado, optou-se por uma pesquisa psicológica na instituição Odontologia para bebês. A dimensão da afetividade nessa área de atuação foi eleita devido ao seu valor clínico.

Saliente-se que, no campo psicológico, há diferentes possibilidades de compreensão da afetividade, sendo que neste estudo houve um interesse por sua configuração na dimensão representacional. Por outro lado, referir-se a discurso é algo complexo, pois abre um campo vasto e rico em autores importantes (Spink, Maingueneau, Guirado, etc.) e pontos de vista, sendo impossível abarcar a totalidade de suas contribuições. Ressalte-se aqui, inclusive, que não se fez "Análise do Discurso", campo com estratégias analíticas específicas, neste estudo, mas debruçouse sobre o discurso à maneira de uma autora-guia e sua produção teórica de uma determinada época.

Em termos conceituais, trabalhou-se na dissertação de mestrado e, portanto, nesta síntese da mesma, inspirado em Guirado (1986 e 1987), a partir da qual a afetividade foi delineada enquanto representações ou imagens (que reconhecem e desconhecem) de relações e vínculos possíveis, por conseguinte, de lugares do profissional e de sua prática, do paciente e do acompanhante, na ordem da posição simbólicoinstitucional-imaginária de agentes institucionais (odontopediatras) na Odontologia para bebês. Explicite-se que essas representações estão articuladas em e são legitimadoras de relações/ vínculos concretos e práticas institucionais que as sustentam.

Por fim, deve-se enfatizar que, com este estudo, objetivou-se, de modo genérico, compreender a afetividade enquanto discurso profissional na instituição Odontologia para bebês, com a consecução de delineamentos configuradores da tríade dentista-paciente-acompanhante, e, quem sabe, transformar, por meio de possíveis efeitos discursivos, relações/vínculos afetivos na área de atuação escolhida. De maneira específica, buscouse acompanhar a hipótese de indiferenciação, concebida como sobreposição de lugares no discurso, e considerar dimensões referentes à idade dos bebês e à experiência profissional.

\section{Metologia}

Houve a realização de uma investigação empírica de cunho qualitativo sobre a afetividade na Odontologia para bebês na cidade de São Paulo. Participaram deste estudo, sendo preservadas suas identidades, três odontopediatras do sexo feminino que trabalhavam com bebês (crianças de até três anos de idade). Duas das participantes eram experientes, com mais de quinze anos de prática profissional, e uma, inexperiente, com menos de três anos de atividade em Odontopediatria.
Por se tratar de um estudo de caráter qualitativo, não houve muitos participantes, pois foram priorizadas a profundidade de investigação com o acompanhamento das dentistas em várias sessões de atendimento e a análise pormenorizada das sessões. Saliente-se também que a escolha apenas de mulheres deve-se à prevalência das mesmas no atendimento odontológico voltado a uma clientela na tenra infância. Quanto à escolha de odontopediatras com diferente maturidade, justificase pela suposição de que a experiência profissional interferiria na afetividade na clínica odontológica com bebês.

Para a realização desta investigação, foram utilizados basicamente como instrumentos: a "Folha de Registro de Observação", com dados gerais (data, número da sessão, nome da dentista, número de funcionários, nome do paciente, nome do acompanhante, dados de identificação do paciente), interações verbais da profissional com pacientes e acompanhantes, bem como indagações à dentista apresentadas ao fim das sessões ("O que foi mais prazeroso nesse atendimento?" "O que foi mais ansiógeno nessa sessão?"), e o "Roteiro de Entrevista Semi-estruturada", com uma solicitação inicial ("Fale um pouco de sua vida na clínica para bebês") e duas solicitações adicionais ("Fale um pouco de sua vida fora do trabalho, comparando com sua vida na clínica para bebês." "Como você se caracteriza como odontopediatra de bebês?"), caso não falassem sobre isso espontaneamente, bem como possíveis indagações formuladas livremente em torno do eixo "relações".

Procederam-se às observações, no total de vinte sessões clínicas das três profissionais, sendo seis referentes a uma odontopediatra experiente, atendendo quatro pacientes de até três anos de idade (um de cada faixa etária: até onze meses, um ano, dois e três anos) em clínica particular, e quatorze concernentes a uma dupla de odontopediatras (uma experiente e outra inexperiente), trabalhando juntas, em uma universidade, frente também a quatro pacientes de mesma faixa etária (um de cada marco), e ainda um extra não previsto, de dois anos de idade. Saliente-se que, sob o modelo de constituição de dupla, uma profissional era quem efetivamente atendia o paciente em cada sessão e a outra a auxiliava. Entrevistas individualizadas (uma com cada participante) também foram realizadas com agendamento prévio; estas foram gravadas e transcritas.

Ressalte-se que o delineamento metodológico das observações, coerente com uma abordagem qualitativa que não se prende à simetria numérica, justifica-se pela facilidade de serem observadas as práticas clínicas dessas profissionais participantes que tinham tais modelos particulares de atendimento.
Agradeço à professora dra. Lígia Assumpção Amaral pela dedicada orientação no mestrado. 
Quanto ao material obtido (discursivo) das observações e entrevistas, inspirado por Guirado (1986), foi submetido a uma análise minuciosa fala por fala, que se preocupou predominantemente com termos repetitivos, aspectos recorrentes e/ou geradores de estranhamento, indicadores de indiferenciação, aspectos referentes à experiência profissional e à idade dos bebês, bem como com nuanças especiais encontradas nas representações. Após isso, houve uma categorização das falas por meio de temas e uma organização temática com base em três eixos referentes aos membros da tríade relacional/vincular na Odontologia para bebês: o lugar do profissional e de sua prática, o lugar do paciente e o lugar do acompanhante. Para cada eixo/lugar, há, portanto, seus temas específicos com descrições analíticas e exemplificações com alguns grifos sinalizadores, bem como alguns sentidos atribuídos.

Finalmente, é necessário enfatizar que a análise construída buscou preservar a invisibilidade das participantes como postura ética de preservação do seu anonimato, de modo que as falas das odontopediatras foram bastante recortadas e não nomeadas, ou associadas a nomes fictícios, com os procedimentos de organização. Além disso, explicitese que os três momentos discursivos (falas em sessões clínicas, respostas às indagações apresentadas ao fim das sessões e material das entrevistas) raramente foram separados e diferenciados por opção analítica, bem como alguns discursos das entrevistas, após perguntas diretivas, não foram cotejados em função da mudança do "lugar" do pesquisador da coleta à análise, e de conseqüentes ajustes necessários, para maior fluidez e menor diretividade.

\section{Leitura do Material}

Utilizou-se como referencial a perspectiva teórica (institucional) de Guirado (1986 e 1987), na qual a afetividade foi delineada enquanto representações ou imagens de relações e vínculos possíveis numa determinada ordem simbólico-institucional, sendo essas representações articuladas em e legitimadoras das práticas concretas que as sustentam.

Essa perspectiva da autora é crivada pelo referencial teórico lacaniano, mas não delimitada/explicada por ele, tão marcada está pelas idéias da Análise Institucional. Partindo de Lacan, mas desenvolvendo seu próprio raciocínio, pensa na afetividade constituindo as relações imaginárias, enquanto representações que reconhecem e desconhecem, imagens, com o que elas possuem de alienação, em posições na rede simbólica. Enfatize-se que, por ser seu recorte muito marcado pelas idéias da Análise Institucional, nos faz pensar em imagens ou representações (indicadores de relações e vínculos possíveis) estruturados simbolicamente na ordem instituída (Guirado, 1986).
Destaque-se, também, que o conceito de instituição utilizado, presente em formulações teóricas da autora, é o desenvolvido por Guilhon de Albuquerque para a análise de instituições concretas, assim retomado por Guirado: "conjunto de práticas sociais que se reproduzem e se legitimam, num exercício incessante do poder; um poder entre agentes, dos agentes com a clientela; um poder na apropriação de um certo tipo de relação como própria..." (1987, p.69, grifos nossos).

Práticas essas, conforme Guirado (1987) bem salientou, sempre implicadas em representações legitimadoras das relações concretas. Desse modo, reconheceu-se que a afetividade se encontra na dimensão representativa nessas e dessas práticas/ relações/vínculos, na ordem simbólico-institucional.

Localizando mais precisamente essa leitura do material, houve a análise da afetividade enquanto representações (com seus reconhecimentos e desconhecimentos) nas falas de agentes institucionais (porta-vozes) da Odontologia para bebês, de modo mais específico, a configuração de lugares imaginados de relações e vínculos possíveis nessa área de atuação na ordem da posição simbólico-institucional de dentistas.

A análise de representações extraídas das falas de odontopediatras será apresentada a seguir, com base em eixos/lugares e seus temas perseguidores dos objetivos desta pesquisa:

\section{O Lugar do Profissional e de sua Prática}

Indiferenciação: nos atendimentos clínicos, as dentistas atribuíam suas próprias falas aos pacientes, ocupando duas posições no discurso. Ora falavam como profissionais, ora como pacientes que, por serem bebês, tinham, algumas vezes, poucos recursos verbais ou estavam sendo oralmente instrumentalizados durante as intervenções. Tal indiferenciação discursiva dos lugares do profissional e do paciente pode ser demonstrada com a seguinte fala: "Meu dentinho vai demorar um pouquinho. $\mathbf{E u}$ sou pequenininha."

De quem é o dentinho: da dentista ou do bebê? Do bebê, mas a profissional verbaliza no lugar do paciente, estabelecendo um diálogo que, na verdade, é um monólogo em que assume dois papéis.

A indiferenciação do profissional em relação ao paciente também pode ser reconhecida no uso peculiar da primeira pessoa do plural durante as sessões clínicas, de modo a haver uma aproximação ou indiscriminação de lugares discursivos. Alguns 
exemplos típicos são: "vamos cuspir." "Vamos sair da cadeira."

Quem vai cuspir? Quem vai sair da cadeira? É o paciente, não este e a profissional. No entanto, não é assim que aparece nas falas das dentistas.

A indiferenciação ainda apareceu no material das entrevistas: "na clínica para bebês (...) eu tenho que estar ali presente no paciente."

Presente onde? Dentro do paciente? Seja enfatizado que, por se pensar nessas profissionais como "agentes institucionais", interessa-nos o modo como suas falas configuram imaginariamente na indiferenciação a "Clientela", reconhecendo e desconhecendo aspectos com implicações práticas.

Experiência profissional: nas participantes experientes (que já adquiriram mais características institucionais de seu lugar/papel), a experiência profissional apareceu remetendo o sofrimento e as dificuldades ao passado ("No início da profissão (...) eu ficava em ansiedade (...) Hoje pode vir!") e/ou como aumento de desgaste ("Por outro lado (...) desgasta muito.") e redução de paciência ("(...) à medida que a gente vai ficando mais velho, a paciência vai diminuindo.") e/ou como aprendizado no posicionamento/imposição de limites ("Hoje, procuro trabalhar buscando o equilíbrio dessa família e impondo coisas que acho que têm que acontecer."). $\mathrm{Na}$ participante inexperiente, a experiência profissional foi um aspecto pouco comentado e, quando men-cionado, reconhecido como sem valor ("Eu acho mais gratificante de tratar do bebê. Não é uma coisa que vai da minha experiência.").

As qualidades de profissionais e de sua prática: muitas vezes, o lugar do profissional e de sua prática, quando diferenciado ou tentando diferenciar-se, apareceu como o dos atributos positivos ("Olha, que legal, o espelhinho! "Tia Paula tá aqui para ajudar."). Poucas vezes, houve o reconhecimento de aspectos difíceis e/ou sofríveis da própria prática ("A tia não tá fazendo nada. A tia só tá querendo cuidar de você."). Além disso, as falhas, as dificuldades e os atributos negativos foram vistos como "exteriores" ao atendimento ("Você chora para todas as músicas. Não vai dar certo."). Tal aspecto expressa a idealização do lugar imaginado, muitas vezes, pelas "agentes institucionais" para si e suas práticas.

O término do atendimento: o término do atendimento foi freqüentemente anunciado, associando-se, muitas vezes, à vivência de prazer ("Abra a boca para acabar depressa ..." "Tá bom. Acabou! Pronto! Viva!"), o que sinaliza dificuldades da prática, constantemente, não reconhecidas na ordem da posição idealizada por "agentes institucionais" para seu fazer. Quando o final não foi "feliz", o que evidencia os aspectos difíceis, o término do atendimento apareceu, pelo contrário, como desprazeroso. Um exemplo disso foi uma das respostas ao que foi mais ansiógeno no decorrer da sessão: "criança gritando no fim. Me irritou!"

A tarefa dentária como meta: a finalidade do atendimento e dos contatos definiu-se como unidimensionalmente dentária ("O mais gostoso foi que vi que ela não tem cárie."). Para a meta ser alcançada, a equipe foi apontada como importante ("Se a equipe não tiver sintonizada (...)") e pareceram ser necessários, muitas vezes, "equilibrismos" profissionais diante das múltiplas demandas, sendo a relação com a tarefa odontológica controladora e normatizadora de outras relações institucionais ("Você tem que considerar uma série de coisas (...) toda aquela técnica que você tem que fazer (...) Você tem que vencer as dificuldades. Você tem que fazer em menor tempo (...) tem que fazer aquela técnica rápido, bem eficiente; o local é pequeno, a criança está se mexendo e você tem que estar preocupado com esta parte.").

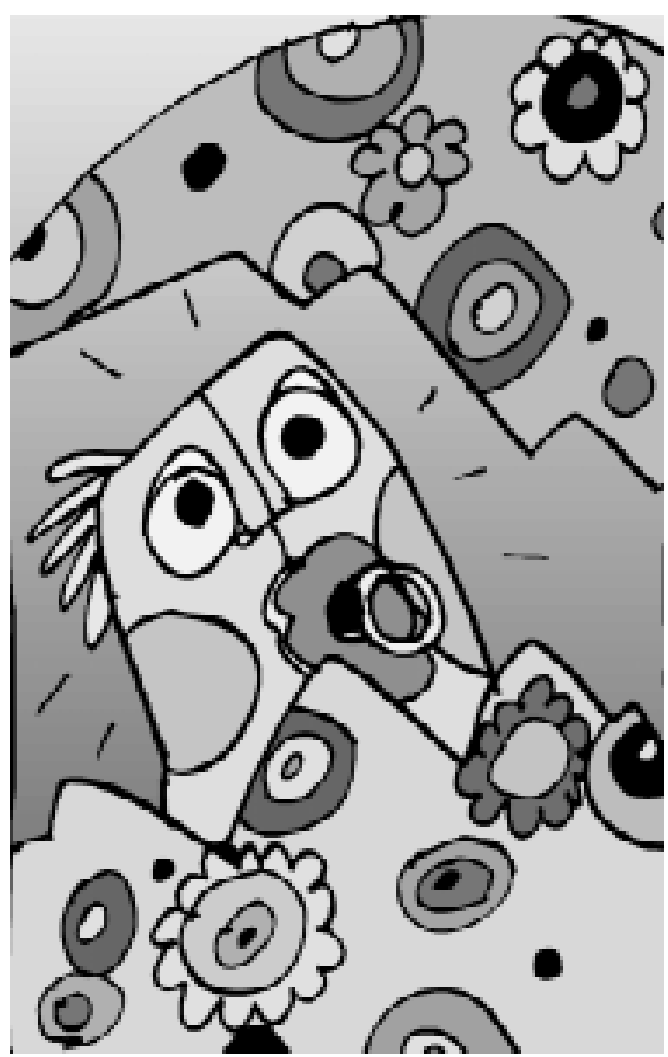

A questão da singularidade: apareceu uma busca e afirmação de singularidade, um lugar imaginado para um "eu" distinto do "grupo de odontólogos", isto é, um espaço para características específicas de cada profissional ("Acho que gosto de atender bebês, porque é uma situação fechada, de controle. Domino aquela situação..."').

Nos atendimentos clínicos, as dentistas atribuíam suas próprias falas aos pacientes, ocupando duas posições no discurso. 
Settings: houve reconhecimentos de aspectos contextuais demarcando especificidades referentes aos settings clínica particular/consultório e universidade ("Essas coisas daqui, bem diferentes do consultório."). Ambos os contextos foram vistos como positivos e negativos. Sobre a prática no consultório, encontraram-se falas como: "Com bebês, no consultório, eu acho mais fácil, pois você tem uma hora inteira." "No consultório particular, acho que é diferente [pior], pois está pagando (...) Talvez você até precise se preocupar mais com os pais no consultório particular; você está pagando." A respeito da prática universitária, foram encontrados exemplos como: "quando aqui na faculdade, eu sinto que, num determinado momento, eu quero dar toda a atenção para a criança, então, dou toda atenção, porque tenho segurança que o pai vai voltar." "Barulho aqui me atrapalha." Tais imagens estão implicadas no modo das "agentes institucionais" se posicionarem com seus pacientes e acompanhantes nesses contextos.

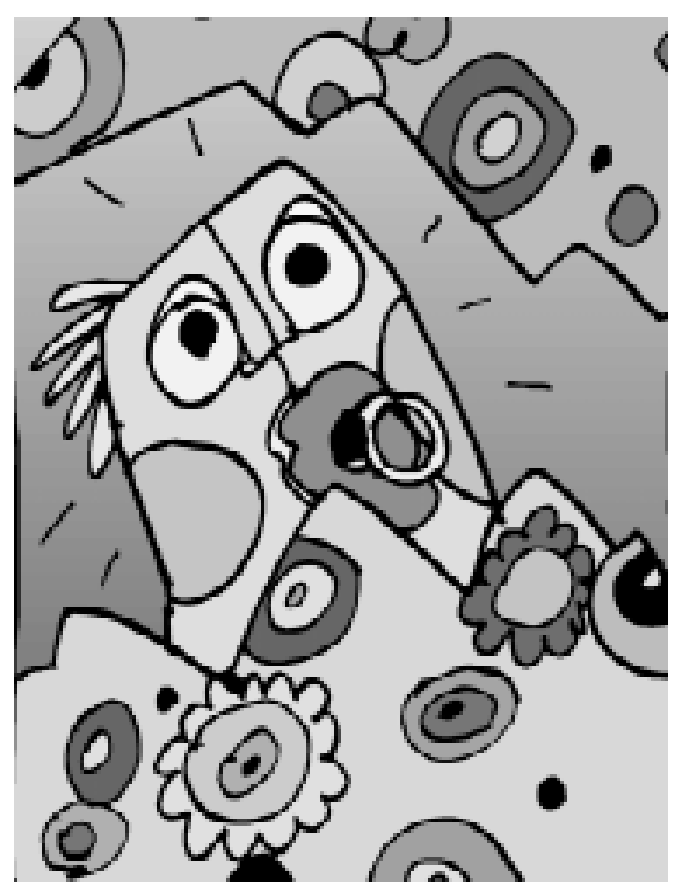

\section{O Lugar do Paciente}

A idade do bebê: a idade apareceu como um aspecto representacional importante nas referências a pacientes, bem como assumiu formas variadas na multiplicidade de falas. Esse aspecto diferenciou bebês de crianças maiores e adultos ("Porque $\boldsymbol{o}$ atendimento de bebês é diferente do atendimento da criança mais velha, pois, em relação ao bebê, é normal o choro (...)" "(...) mais fácil do que lidar com adulto"). Além disso, a idade do bebê normatizou dimensões do atendimento, o que pode ser inferido do "ter que" em função do etário ("Lidar com bebê (...) tem que ter mais paciência, tem que gostar mais.").

O lugar imaginado do bebê, legitimador de um certo tipo de relações afetivas com a clientela, tem marcas etárias que podem ser vistas como positivas ou negativas ("Lidar com bebê, eu acho uma coisa muito fácil (...)" "... Difícil questão de idade: faz birra, chora, não entende o que se diz."). Pareceu ainda distinto o suscitado pela idade, quando apropriações e/ou justificativas psíquicas (explicações psicologizantes), referentes às condutas dos pacientes, ocorreram ou não ("Acima de três anos, relaciona causa e efeito, a criança já entende por que está sentada na cadeira abrindo a boca.").

Contatos não estritamente dentários: o paciente, na ordem imaginário-simbólico-institucional de "agentes institucionais", ocupou um lugar de contatos não estritamente dentários ("Mônica, tia pode ou não cantar para você?"), provavelmente suscitado por sua idade, mas deve-se ressaltar que a finalidade dos atendimentos foi representada como odontológica, pois a meta se delineou como dentária na Odontologia para bebês.

Foram reconhecidas falas carinhosas/infantilizadas e a mediação do lúdico nos contatos com os pacientes. As falas infantilizadas utilizaram, por exemplo, atributos positivos e diminutivos (" $E$, esse querido, como vai?" "Você conhece esse ventinho aqui?"). O lúdico apareceu em várias representações ("Olha que bolinha linda, essa!"), inclusive de forma ambivalente ("Mas sem chorar, viu? Senão, não tem bichinho para segurar.").

Uma outra presença de indiferenciação: os "bichinhos dos dentes" pareceram ser instrumentos de metamensagens remetidas aos pacientes, sendo dispositivos para essa outra forma de indiferenciação, a sobreposição de lugares entre tais "bichinhos" e os bebês atendidos, da qual se infere que estes últimos seriam vistos "dentro da cavidade oral".

Alguns exemplos dessa forma de indiferenciação :"tia tá fazendo o bichinho parar de chorar. Ele tá pulando assim, assim." "Agora vou passar um remedinho para o bichinho dormir."

Indaga-se: quem está chorando? Pulando? Quem vai dormir? O bichinho da cárie ou o paciente?! Os exemplos apresentados mostram as imagens do paciente que emergem nas e das relações e práticas concretas na instituição Odontologia para bebês.

Empecilho: o paciente apareceu, muitas vezes, no lugar de obstáculo ao profissional e à sua prática, até a si próprio ("Sem a mão. Não pode pôr a mão. Caso contrário, estraga." "Alice, pára, pára! Você está se machucando sozinha."). 
O paciente é, inúmeras vezes, visto como empecilho, pois, quando se defronta com as intervenções institucionais, está em tensão com elas no jogo de domínio e resistências nas relações com "agentes institucionais".

\section{O Lugar do Acompanhante}

A idade do bebê: a idade do bebê pareceu um importante aspecto a ser considerado nas representações do lugar do acompanhante, inferido, por exemplo, da mediação deste na relação profissional-paciente ("Sabia que eu gosto muito de sua mãe, sabia?!"), bem como verificado no reconhecimento de uma especificidade para a relação decorrente da idade dos pacientes ("(...) Acima de três anos, a maioria das vezes, a mãe não faz questão se fica junto na sala, já não precisa dar tanto a mãozinha nem ficar do lado, dar um apoio."). Tal aspecto é significativo, pois salienta, mais uma vez, os sentidos do etário nas possibilidades da afetividade na Odontologia para bebês.

Contatos dentários: reconheceu-se o lugar do acompanhante, nas imagens de "agentes institucionais", como o dos contatos dentários (referentes ao odontológico propriamente dito) com finalidades dentárias. Solicitação de informações sobre o paciente ("Mãe, ela já tá comendo comida?"), de participação em técnicas ("Segura a mão, apóia o cotovelo.") e também explicações e esclarecimentos odontológicos ("Cárie, ele não tem. Essas manchas amarelas são tudo placa bacteriana e tártaro...") foram muito comuns.

Empecilho: os acompanhantes foram reconhecidos como obstáculos, assim como os pacientes, provavelmente por serem vistos como prolongamentos destes por causa da faixa etária da clientela na instituição Odontologia para bebês.

Alguns exemplos do lugar de empecilho do acompanhante são: "Então, é a incompreensão dos pais, o que me desgasta." "O que eu acho mais complicado é que, às vezes, a mãe..." "(...) os pais; você tem que tratar logo!"

\section{Discussão}

Com base em Guirado (1986 e 1987), a afetividade foi configurada na dimensão representacional das relações e vínculos possíveis, tendo como pressuposto que as representações/imagens reconhecem e desconhecem aspectos na ordem de suas posições simbólico-institucionais, legitimando os contornos relacionais e vinculares, as práticas institucionais concretas que as sustentam, conforme as figuram.

Falar de afetividade enquanto representações/ imagens na Odontologia para bebês e de suas implicações (com seus reconhecimentos e desconhecimentos) nas práticas concretas que as sustentam é fazer referência a diferentes posições: a de dentistas (agentes institucionais dessa área de atuação), a de pacientes (clientela) e a de acompanhantes (como prolongamento dessa clientela). Nesta investigação, escolheu-se a perspectiva das representações profissionais, pois agentes institucionais, segundo Guilhon de Albuquerque apud Guirado (1987), estabelecem com a clientela um exercício de poder, apropriando-se de um certo tipo de relação como própria.

Pode-se delinear, na leitura do material, os lugares que se instituem do profissional e de sua prática, do paciente e do acompanhante (com suas características/temas) configuradores da afetividade enquanto imagens profissionais das relações e vínculos possíveis na instituição Odontologia para bebês.

Com base nesses lugares e temas, perseguidores dos objetivos desta pesquisa, dar-se-á encaminhamento a esta discussão a partir de então, com o suporte teórico de Guirado (1986 e 1987), que atravessa todo este estudo, bem como contemplando autores do terreno psi aplicado à Odontologia, como Aberastury, Moraes e Pessoti etc.

Referente ao lugar do profissional e de sua prática, a hipótese de indiferenciação foi corroborada. As dentistas, muitas vezes, atribuíram suas próprias falas aos pacientes, ocupando duas posições no discurso: ora falavam como profissionais, ora como pacientes. Tal sobreposição profissional-paciente é signi-ficativa, já que, a partir de Guilhon de Albuquerque apud Guirado (1987), pode-se pensar no exercício de poder entre agentes institucionais e clientela. Através dessa apropriação da relação por agentes institucionais, há a invisibilidade da clientela, o que é perigoso, principalmente em relações de ajuda em que há sofrimento de pacientes (e sinalizações deste) por causa de procedimentos técnicos. Saliente-se que, segundo Klatchoian (1992), a identificação profissional-paciente aparece na Odontopediatria como um todo, no entanto, pensa-se, a partir deste estudo, que na Odontologia para bebês ela é mais freqüente por ser suscitada pela tenra idade da clientela.

Sobre esse mesmo eixo/lugar do profissional e de sua prática, destaque-se que a experiência profissional (prevista como importante nos objetivos desta pesquisa) e a ênfase nos atributos positivos de dentistas e suas práticas também foram dimensões significativas. Por exemplo, as profissionais experientes colocaram constantemente as dificuldades e dores em um passado remoto caracterizado pela inexperiência. Por outro lado, o sofrimento foi dificilmente reconhecido pelas
Os acompanhantes foram reconhecidos como obstáculos, assim como os pacientes, provavelmente por serem vistos como prolongamentos destes por causa da faixa etária da clientela na instituição Odontologia para bebês. 
odontopediatras em suas práticas, pois uma imagem profissional idealizada não permitiu tal ferida narcísica.

A partir de Guirado (1986 e 1987), pode-se comentar que tais representações da prática profissional como inteiramente prazerosa e da experiência profissional como condição para não se ter dificuldades carregam em si muitos desconhecimentos, muita alienação. É difícil para agentes institucionais verem a si e seus procedimentos implicados na vivência do paciente, sendo que a idealização de seu lugar profissional ainda se revela mais intensamente, revestida pelos sentidos da experiência.

No entanto, não se pode esquecer de que há um pesar nas práticas odontológicas com bebês, tanto que o término do atendimento é constantemente anunciado ou visto como prazeroso nas sessões. Em decorrência disso, realça-se a importância de o surgimento de possibilidades do sofrimento de todos os envolvidos ser compartilhado e acolhido. Sofrimento este que se relaciona com as características institucionais da Odontologia para bebês, mesmo que possa presentificar também conteúdos orais inconscientes, o que foi sinalizado por Aberastury (1978 e 1996).

Enfatize-se aqui que, se dentistas não reconhecerem o sofrimento implicado em suas práticas e as dificuldades de seu papel profissional, sua imagem idealizada legitimará apenas algumas possibilidades de afetividade nas relações e nos vínculos concretos, atribuindo os obstáculos, as dores, exclusivamente aos pacientes e, em caso de relações triádicas como na Odontologia para bebês, aos acompanhantes também. Foi isso o que se percebeu neste estudo!

Ressalte-se aqui, a partir de Guirado (1986 e 1987), que essas possibilidades de afetividade e suas representações se instituem na tensão e apropriação de um certo tipo de contato entre "agentes institucionais" (dentistas, cujas intervenções concretizam a "ação institucional" da Odontologia para bebês) e "clientela" (alvo dessa ação, que inclui o acompanhante nessa área de atuação).

A respeito do lugar do profissional e de sua prática, com base na mesma autora-guia ainda foram encontradas imagens que constroem uma singularidade para cada odontopediatra e variantes contextuais em suas intervenções, sendo que, na teia institucional da Odontologia para bebês, a tarefa odontológica e seus resultados pareceram ser o totem, pois a grande meta se definiu como unidimensionalmente dentária. A relação profissional mostrou-se ser, sobretudo, com sua tarefa e esta ser definidora de outras relações e vínculos na tríade dentista-paciente-acompanhante. O lugar do profissional, desse modo, foi percebido como de força e domínio, mas também de muita fragilidade, sendo o dentista um "equilibrista" diante de múltiplas demandas, como bem o nomearam Moraes e Pessoti (1993).

Mesmo tendo a finalidade, na Odontologia para bebês, se figurado como especificamente técnica, destaque-se, em relação ao lugar do paciente, que os contatos com bebês (meios para se chegar à meta odontológica) se desenharam como não dentários (através do lúdico, etc.) A idade da clientela (prevista como significativa nos objetivos desta pesquisa) é de suma importância nisso; aliás, o etário suscitou múltiplos posicionamentos dos pacientes nas relações em que "agentes institucionais" os viram, muitas vezes, como obstáculos (resistência à "ação institucional") e/ou indiferenciados dos "bichinhos do dente" num jogo institucional de domínio e poder no discurso em que se reconhecem e desconhecem aspectos, legitimando práticas, para usar a terminologia de Guirado.

Quanto aos acompanhantes, estes, na visão de odontopediatras, ocuparam também o lugar de empecilho às práticas odontológicas por serem vistos como prolongamentos dos bebês. Com base em Guirado (1986 e 1987), pode-se pensar no binômio bebê-acompanhante resistindo à "ação institucional" na reprodução de relações e poder. Acrescente-se que com pai, mãe, avó etc., as profissionais ainda se relacionavam explicando, orientando, solicitando participação em técnicas, isto é, de modo formal. Será que os contatos não dentários só são legítimos com seres humanos na tenra infância na ordem simbólico-institucional da Odontologia para bebês? Deve-se enfatizar, a respeito da importância do etário nessa área, que surgiram peculiaridades nas configurações relacionais entre odontopediatras e acompanhantes decorrentes da idade dos bebês; a título de exemplificação, o papel de pais, avós etc. de mediadores da relação profissional-paciente.

Enfim, saliente-se que, se a afetividade na Odontologia para bebês se configurou de um jeito característico neste estudo (a partir dos reconhecimentos e desconhecimentos do pesquisador), transformações são vistas como possíveis, desafixando representações, na instituição investigada, nas relações entre "agentes institucionais" e "clientela", o que se traduz, por implicação lógica, em mudanças concretas nas práticas nessa área de atuação e em suas relações com outras instituições, como a Medicina e a Psicologia.

Aliás, há pouco tempo, a Odontologia apresentou modificações importantes com as práticas com bebês, como enfatizaram Walter, Ferelle e Issao (1996) e Corrêa e Maia (1998). Por que, então, deixar de renovar a sua história?! 
Ricardo Azevedo Barreto Avenida Deputado Sílvio Teixeira, 990. Edifício Wembley Park, apto 1103. Bairro Jardins. CEP: 49025 - 100. Aracaju-Sergipe. Tel: (79) 2310299 ou (79) 2318496

Recebido 25/01/01 Aprovado 23/11/02

Aberastury, A. (1978). El psicoanálisis de niños y sus aplicaciones. 3.ed. Buenos Aires: Paidós.

(1996). Abordagens à psicanálise de crianças. Trad.

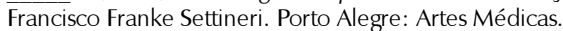

Corrêa, M.S.N. \& Maia, M.E.S (1998). Técnicas de abordagem. Em M.S. N.Corrêa, Odontopediatria na primeira infância (pp. 165177). São Paulo: Santos.

Guirado, M. (1986). Instituição e relações afetivas. São Paulo: Summus.
(1987). Psicologia institucional. São Paulo: EPU.

Klatchoian, D.A. (1992). A relação dentista-criança. Dissertação de Mestrado, Pontifícia Universidade Católica de São Paulo, São Paulo.

Moraes, A.B.A. \& Pessoti, I. (1993). A psicologia e a relação cirurgião-dentista-paciente. Em J.G.Paiva \& J.H.Antoniazi, Endodontia - bases para a prática clínica (pp.237-50). 2.ed. Porto Alegre: Artes Médicas.

Walter, L.R.F., Ferelle, A., Issao, M. (1996). Odontologia para o bebê. Porto Alegre: Artes Médicas.
Referências

bibliográficas 